\title{
Simulated Annealing para Melhoria do Sequenciamento de Tarefas em uma Fábrica.
}

\author{
Aníbal T. de Azevedo (PQ), Nathália B. da Silva (IC)
}

\section{Resumo}

A eficiência de um chão de fábrica pode ser melhorada dependendo da forma com que as operações de sequenciamento de tarefas são distribuídas dentro do ambiente de processamento. Dessa forma, se faz necessária a otimização tanto do sequenciamento de tarefas quanto da configuração do layout da fábrica. Portanto, neste projeto de pesquisa será apresentado um Simulated Annealing combinado com a simulação para a avaliação e melhoria de diferentes propostas de sequenciamento de tarefas e de layout do chão de fábrica, buscando-se a minimização do tempo total de processamento.

Palavras Chave: Sequenciamento de Tarefas, Simulated Annealing, Otimização Combinatória.

\section{Introdução}

As principais decisões relacionadas à programação da produção são a designação de tarefas a máquinas e a programação das tarefas em cada máquina (ARENALES et. al. 2007). No presente trabalho, a medida de desempenho utilizada para avaliar a qualidade do programa de produção será o makespan, que é o instante de término de processamento de todas as tarefas a serem processadas (ARENALES et. al. 2007).

Um problema anterior à programação da produção é a determinação do layout do chão de fábrica. No contexto apresentado, a localização das máquinas dentro da fábrica impacta de forma direta os resultados da produção, considerandose questões como distância e frequência de viagens.

Portanto, o projeto de pesquisa apresentará um Simulated Annealing capaz de encontrar a melhor solução para um determinado problema de sequenciamento de tarefas fornecido por (ZAHARI et al. 2011). Tal algoritmo realiza uma busca local capaz de escapar de ótimos locais, permitindo movimentos para soluções com valor da função objetivo piores que o valor da função objetivo da solução corrente. Assim, ele será utilizado também para a avaliação de diferentes layouts e o impacto destes nos resultados obtidos. Além disso, o software de simulação Flexsim será utilizado para avaliação das diferentes propostas.

\section{Resultados e Discussão}

O problema proposto é um job shop clássico, no qual cada tarefa é processada nas máquinas de acordo com um roteiro preestabelecido. Determinando-se previamente o layout, o algoritmo buscará a melhor sequência de tarefas, como observa-se no exemplo da figura 1.

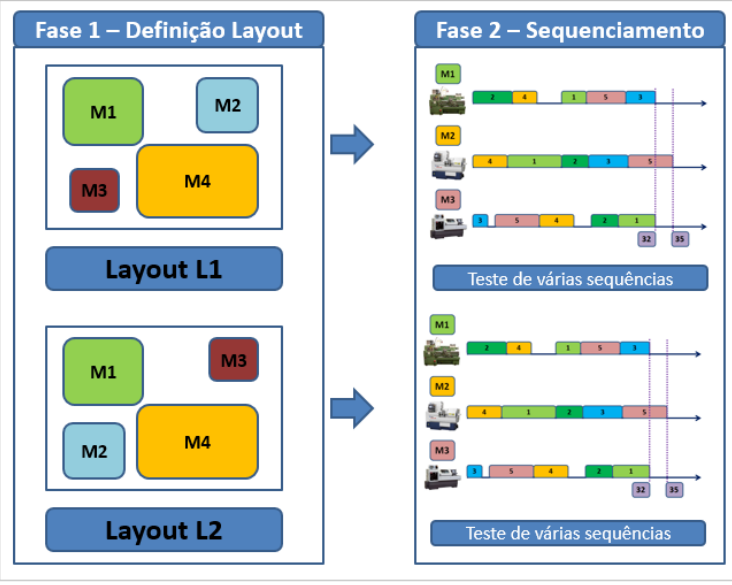

Figura 1. Exemplo do processo realizado.

A partir dos dados fornecidos por (ZAHARI et al. 2011), o Simulated Annealing foi desenvolvido no software de programação Mathematica, sendo encontradas as melhores soluções para cada tipo de layout.

\section{Conclusões}

Os resultados obtidos por meio do Simulated Annealing mostraram a importância de uma programação adequada da produção assim como da escolha do layout do chão de fábrica.

\section{Agradecimentos}

Ao Prof. Dr. Aníbal, pela oportunidade, orientação e apoio na elaboração deste trabalho.

À Unicamp, pela oportunidade oferecida, e ao Serviço de Apoio ao Estudante, pelo suporte necessário para a pesquisa.

A todos que direta ou indiretamente contribuíram para a realização deste trabalho.

\footnotetext{
ARENALES, Marcos, et. al. Pesquisa Operacional para Cursos de Engenharia. Rio de Janeiro: Elsevier, 2007.

2 TAHA, Z.; TAHIRI, F.; ZUHDI, A., Job Sequencing and Layout Optimization in Virtual Production Line, J. of Quality, v.18, no. 4, p. 351-374, 2011.
} 